\section{International Scientific Journal Theoretical \& Applied Science}

\author{
p-ISSN: 2308-4944 (print) e-ISSN: 2409-0085 (online) \\ Year: 2017 Issue: $04 \quad$ Volume: 48
}

Published: $30.04 .2017 \quad$ http://T-Science.org
Denis Chemezov

Master of Engineering and Technology, Corresponding

Member of International Academy of Theoretical and Applied Sciences, Lecturer of Vladimir Industrial College, Russian Federation chemezov-da@yandex.ru

Tatyana Lukyanova Lecturer of Vladimir Industrial College, Russian Federation

Elena Kiseleva SECTION 19. Management. Marketing. Public administration.
Master of Industrial Training, Vladimir Industrial
College, Russian Federation

\title{
MANAGEMENT OF THE PRODUCTION PROCESSES OF THE ENTERPRISE ON THE RELEASE OF THE AUTOMOTIVE COMPONENTS
}

Abstract: In the article it was made the analysis of the basic production processes of the parts manufacturing at JSC «Zavod «Avtopribor». Recommendations for the cost reduction and time for manufacturing of the products at the enterprise are given.

Key words: a production, a part, an operation, a technological process.

Language: Russian

Citation: Chemezov D, Lukyanova T, Kiseleva E (2017) MANAGEMENT OF THE PRODUCTION PROCESSES OF THE ENTERPRISE ON THE RELEASE OF THE AUTOMOTIVE COMPONENTS. ISJ Theoretical \& Applied Science, 04 (48): 166-176.

Soi: http://s-o-i.org/1.1/TAS-04-48-28 Doi: crostef https://dx.doi.org/10.15863/TAS.2017.04.48.28

\section{УПРАВЛЕНИЕ ПРОИЗВОДСТВЕННЫМИ ПРОЦЕССАМИ ПРЕДПРИЯТИЯ ПО ВЫПУСКУ АВТОМОБИЛЬНЫХ КОМПОНЕНТОВ}

Аннотация: В статье был выполнен анализ базовых производственных прочессов изготовления деталей на ОАО «Завод «Автоприбор». Даны рекомендаџии по снижению затрат и времени на изготовление продукиии на предприятии.

Ключевые слова: производство, деталь, операция, технологический процесс

\section{Введение}

Любой выполняемый производственный процесс [1] на предприятиях сопровождается различного рода потерями, которые приводят к снижению производительности изготовления продукции и необоснованному увеличению потребления ресурсов.

Внедрение на ОАО «Завод «Автоприбор» (Владимир, Россия) бережливого производства способствовало обеспечению производства по заказу клиентов, уменьшению затрат и одновременному повышению качества выпускаемой продукции, устранению потерь времени, труда и материалов [2; 3]. Переход на бережливое производство стал возможен при соблюдении на предприятии следующих условий: качество процессов, надежность технологического оборудования, организация рабочего места, гибкость производства и предсказуемость процессов. Рассмотрим основные потери и методы их устранения при выполнении производственных процессов на ОАО «Завод «Автоприбор».

\section{Материалы и методы исследования}

Объектами исследования являлись производственные процессы изготовления автомобильных компонентов, выполняемые в различных цехах ОАО «Завод «Автоприбор».

Организация производственного процесса направлена на достижение оптимального процесса. Оптимальный производственный процесс должен состоять только из действий, увеличивающих добавленную стоимость продукции. Выполняемые действия, не создающие добавленную стоимость продукции, расцениваются как потери.

Схематичное описание рациональной длительности изготовления детали «Втулка» представлено на рис. 1. 


\begin{tabular}{|c|c|c|c|c|c|c|}
\hline Impact Factor: & $\begin{array}{l}\text { ISRA (India) } \\
\text { ISI (Dubai, UAF } \\
\text { GIF (Australia) } \\
\text { JIF }\end{array}$ & $\begin{array}{l}=1.344 \\
=0.829 \\
=0.564 \\
=1.500\end{array}$ & $\begin{array}{l}\text { SIS (USA) } \\
\text { PИНЦ (Russia) } \\
\text { ESJI (KZ) } \\
\text { SJIF (Morocco) }\end{array}$ & $\begin{array}{l}=0.912 \\
=0.234 \\
=\mathbf{3 . 8 6 0} \\
=\mathbf{2 . 0 3 1}\end{array}$ & $\begin{array}{l}\text { ICV (Poland) } \\
\text { PIF (India) } \\
\text { IBI (India) }\end{array}$ & $\begin{array}{l}=6.630 \\
=1.940 \\
=4.260\end{array}$ \\
\hline
\end{tabular}

84-04-141 «Втулка»

\begin{tabular}{|c|c|c|c|c|c|c|c|}
\hline Onep.260-340 & & $470-520$ & & $730-980$ & & $1080-1090$ & $465,7 \mathrm{M} \mid \mathrm{IIIIII}$ \\
\hline 173,4 MMI & & 28 МЕप & & 242,5 мजा & & $21,8 \mathrm{MMII}$ & \\
\hline & Цех 14 Никель & & Цех 14 Азот & & $\begin{array}{l}\text { Цех } 48 \text { Серебро } \\
\text { Хим. пасс }\end{array}$ & & 111 дмсй \\
\hline & 3 д & & 5 дней & & 3 днв & & \\
\hline
\end{tabular}

Фактически длителыность нгготовления

\section{По МСД Кнд. № $120314 \quad 204$ да⿴囗十}

Рисунок 1 - Длительность изготовления детали «Втулка».

На рис. 2 представлена схема сокращения времени изготовления деталей на механическом участке. В соответствии с технологическим процессом на механическом участке есть группы металлообрабатывающих станков, слесарное отделение и отдел технического контроля (ОТК). Лимитирующее время обработки детали приходится на токарную операцию. Передача заготовок между станками осуществляется по одной штуке или партией по 10 штук.

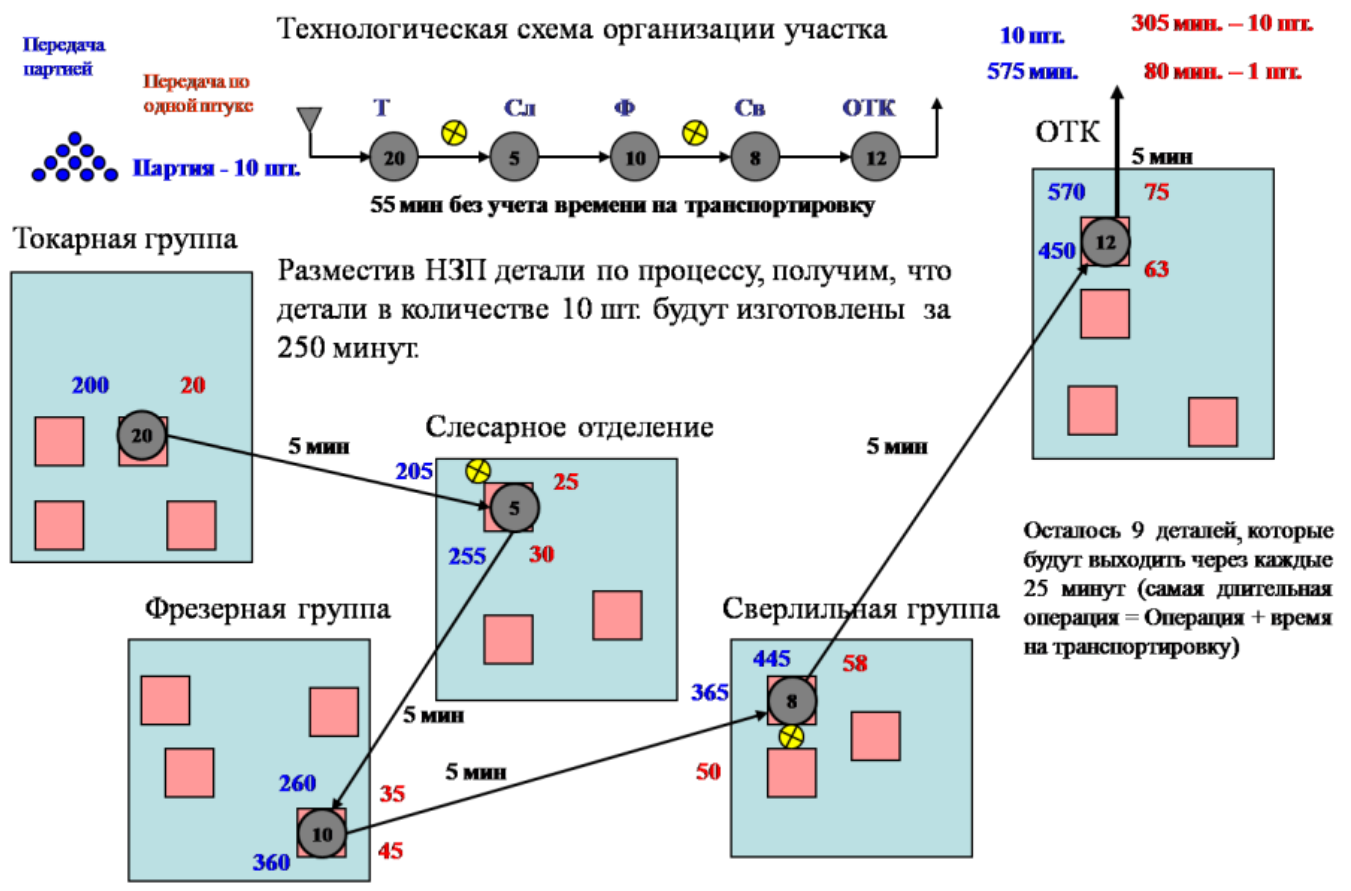

Рисунок 2 - Сокращение времени изготовления деталей.

Разница во времени объясняется тем, что при передаче деталей между станками партией они пролеживают на оборудовании.

Выполним расчет производственной мощности участка и необходимое количество незаконченного производства для выполнения задания. Участку необходимо комплектовать каждый месяц:

1-ПС90А - моторкомплект, состоящий из 5 наименований с общим количеством ДСЕ [4] (детали и сборочные единицы) 20 шт.
5-ГТУ - моторкомплект, состоящий из 8 наименований с общим количеством ДСЕ 90 шт.

1-ЭУ - моторкомплект, состоящий из 8 наименований с общим количеством ДСЕ 16 шт.

Итого за 21 день требуется комплектовать 7 различных двигателей (126 деталей). Суточная программа выпуска 126/21 = 6 дет/сутки. Темп производства на одну смену $T=480 / 6=80$ мин $/ 1$ смена. График комплектования изделий представлен на рис. 3. 


\begin{tabular}{l|lrl|l|ll} 
& ISRA (India) & $=\mathbf{1 . 3 4 4}$ & SIS (USA) & $=\mathbf{0 . 9 1 2}$ & ICV (Poland) & $=\mathbf{6 . 6 3 0}$ \\
Impact Factor: & ISI (Dubai, UAE) $=\mathbf{0 . 8 2 9}$ & PUHU (Russia) $=\mathbf{0 . 2 3 4}$ & PIF (India) & $=\mathbf{1 . 9 4 0}$ \\
& GIF (Australia) & $\mathbf{0 . 5 6 4}$ & ESJI (KZ) & $=\mathbf{3 . 8 6 0}$ & IBI (India) & $\mathbf{4 . 2 6 0}$
\end{tabular}

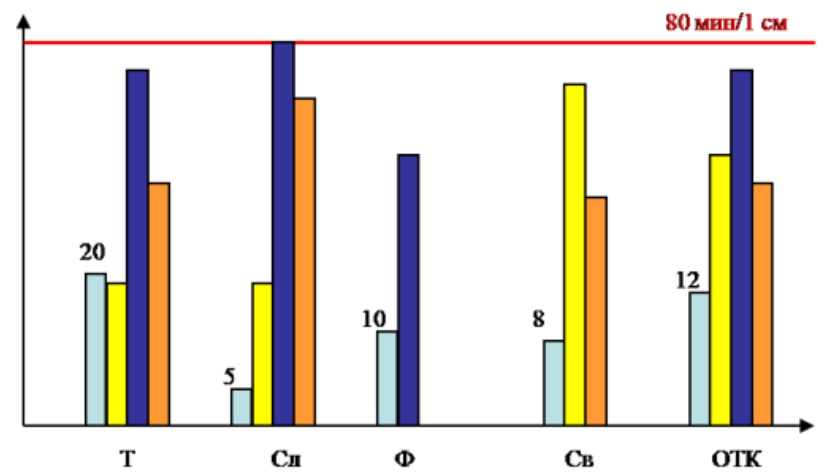

Рисунок 3 - График комплектования.

Диаграмма показывает, что участку для выполнения плана надо работать в одну смену.

Для выполнения производственного задания на участке для каждого наименования рассчитываются и устанавливаются заделы готовых деталей и стандартный размер незаконченного производства. Планирование изготовления деталей на различных участках осуществляется автоматически, по последовательности отбора готовой продукции последующим участком.

Планирование процессов изготовления некоторых деталей представлено на рис. 4 - 7 .

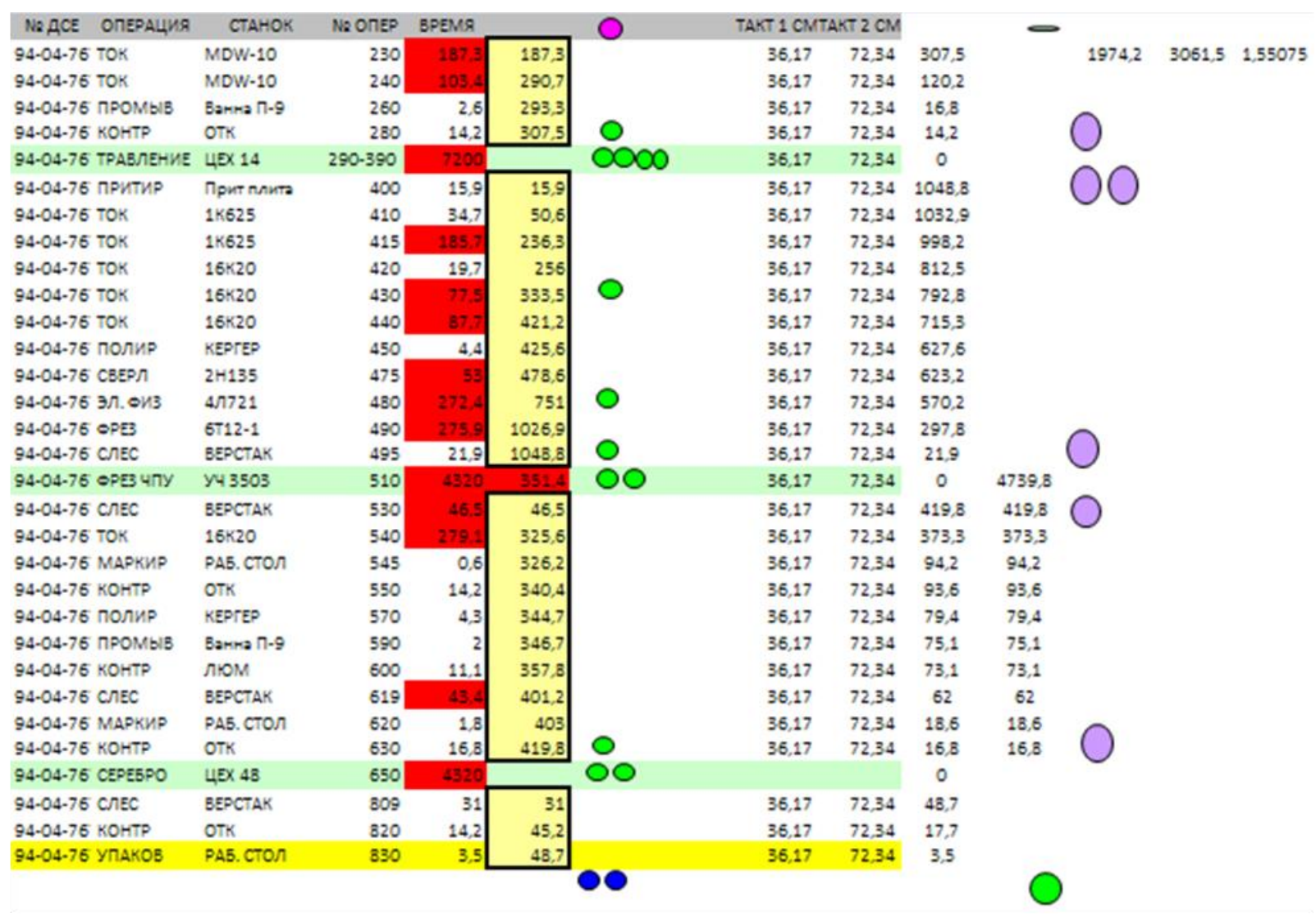

Рисунок 4 - Планирование процесса изготовления детали 94-04-767 «Лабиринт». 


\begin{tabular}{l|lrl|l|ll} 
& ISRA (India) & $=\mathbf{1 . 3 4 4}$ & SIS (USA) & $=\mathbf{0 . 9 1 2}$ & ICV (Poland) & $=\mathbf{6 . 6 3 0}$ \\
Impact Factor: & ISI (Dubai, UAE) $=\mathbf{0 . 8 2 9}$ & PUHU (Russia) $=\mathbf{0 . 2 3 4}$ & PIF (India) & $=\mathbf{1 . 9 4 0}$ \\
& GIF (Australia) & $\mathbf{0 . 5 6 4}$ & ESJI (KZ) & $=\mathbf{3 . 8 6 0}$ & IBI (India) & $\mathbf{4 . 2 6 0}$
\end{tabular}

\begin{tabular}{|c|c|c|c|c|c|c|c|c|c|c|}
\hline Na ДCE OПЕРАЦИЯ & CTAHOK & N2 ONEP & BPEMA & & & $\mathrm{KT} 1 \mathrm{CMT}$ & $\mathrm{KT} 2 \mathrm{CM}$ & & & \\
\hline $94-04-11$ TOK & $16 \times 20$ & 190 & 6,7 & 6,7 & & 36,17 & 72,34 & 6,7 & & 0,09677 \\
\hline $94-04-11$ TOK 4ा7У & $16 A 20$ & 200 & 19,2 & 25,9 & & 36,17 & 72,34 & 25,9 & 665,6 & 18,402 \\
\hline 94-04-11 TOK 4กy & $16 A 20$ & 210 & 14,8 & 40,7 & & 36,17 & 72,34 & 40,7 & & \\
\hline 94-04-11 шлие & "Универсал" & 220 & 12,3 & 53 & & 36,17 & 72,34 & 53 & & \\
\hline 94-04-11 СВЕРЛ & $2 \mathrm{H} 135$ & 230 & 6,6 & 59,6 & & 36,17 & 72,34 & 59,6 & & \\
\hline $94-04-11$ CIEC & BEPCTAK & 240 & 4,2 & 63,8 & & 36,17 & 72,34 & 63,8 & & \\
\hline $94-04-11$ OPEB & $6712-1$ & 250 & 11,7 & 75,5 & & 36,17 & 72,34 & 75,5 & & \\
\hline $94-04-11$ CIEC & BEPCTAK & 260 & 8 & 83,5 & & 36,17 & 72,34 & 83,5 & & \\
\hline $94-04-11$ OPE3 & $6712-1$ & 270 & 19,8 & 103,3 & & 36,17 & 72,34 & 103,3 & & \\
\hline $94-04-11$ CIEC & BEPCTAK & 290 & 13,4 & 116,7 & & 36,17 & 72,34 & 116,7 & & \\
\hline $94-04-11$ ПPOMb/B & Bamma 7-9 & 300 & 0,6 & 117,3 & & 36,17 & 72,34 & 117,3 & & \\
\hline 94-04-11 KOHTP & OTK & 310 & 37 & 154,3 & & 36,17 & 72,34 & 154,3 & & \\
\hline 94-04-11 НИКЕЛЬ & $4 \equiv \times 14$ & $320-380$ & $4320^{\circ}$ & & 3 ana & 36,17 & 72,34 & & & \\
\hline 94-04-11 แлие & $3 \pi 741$ & 390 & 6,6 & 6,6 & & 36,17 & 72,34 & 160,9 & & \\
\hline 94-04-11 แлиอ & $3 / 741$ & 400 & 2,1 & 8,7 & & 36,17 & 72,34 & 163 & & \\
\hline $94-04-11$ กPOMblB & Bamma 7-9 & 420 & 0,6 & 9,3 & & 36,17 & 72,34 & 163,6 & & \\
\hline $94-04-11$ KOHTP & OTK & 440 & 3 & 12,3 & & 36,17 & 72,34 & 166,6 & & \\
\hline 94-04-11 A3OT & $4 E \times 14$ & $450-610$ & 7200 & & 5 a & 36,17 & 72,34 & & & \\
\hline 94-04-11 шлие & $3 \pi 741$ & 620 & 6,4 & 6,4 & & 36,17 & 72,34 & 173 & & \\
\hline 94-04-11 шлиө & $3 \pi 741$ & 630 & 1,9 & 8,3 & & 36,17 & 72,34 & 174,9 & & \\
\hline 94-04-11 шлие & "УнИверСАЛ" & 640 & 5,6 & 13,9 & & 36,17 & 72,34 & 180,5 & & \\
\hline $94-04-11$ TOK & $1 K 62$ & 645 & 33,3 & 47,2 & & 36,17 & 72,34 & 213,8 & & \\
\hline 94-04-11 шлиө & "Универсал" & 650 & 6 & 53,2 & & 36,17 & 72,34 & 219.8 & & \\
\hline 94-04-11 KOHTP & OTK & 655 & 16 & 69,2 & & 36,17 & 72,34 & 235,8 & & \\
\hline 94-04-11 шлие & $3 M 151 B$ & 660 & 5,8 & 75 & & 36,17 & 72,34 & 241,6 & & \\
\hline 94-04-11 МАРКИP & PA5.CTOЛ & 665 & 0,6 & 75,6 & & 36,17 & 72,34 & 242,2 & & \\
\hline $94-04-11 \mathrm{CnEC}$ & BEPCTAK & 670 & 23,3 & 98,9 & & 36,17 & 72,34 & 265,5 & & \\
\hline 94-04-11 חPOMblB & Bamma ก-9 & 685 & 0,6 & 99,5 & & 36,17 & 72,34 & 266,1 & & \\
\hline $94-04-11$ KOHTP & MATHИT & 690 & 30 & 129,5 & & 36,17 & 72,34 & 296,1 & & \\
\hline $94-04-11$ กPOMb/B & Bamma $7-9$ & 700 & 0,6 & 130,1 & & 36,17 & 72,34 & 296,7 & & \\
\hline $94-04-11$ KOHTP & OTK & 710 & 20 & 150,1 & & 36,17 & 72,34 & 316,7 & & \\
\hline 94-04-11 CEPE5PO & $48 \times 48$ & 650 & 4320 & & 00 & 36,17 & 72,34 & & & \\
\hline $94-04-11 \mathrm{CnEC}$ & BEPCTAK & 809 & 13 & 13 & & 36,17 & 72,34 & 329,7 & & \\
\hline 94-04-11 KOHTP & OTK & 820 & 4 & 17 & & 36,17 & 72,34 & 333,7 & & \\
\hline 94-04-11 УПАКOB & PA5. CTOЛ & 830 & 0,3 & 17,3 & & 36,17 & 72,34 & 334 & & \\
\hline
\end{tabular}

Рисунок 5 - Планирование процесса изготовления детали 94-04-1151 «Лабиринт». 


\begin{tabular}{|c|c|c|c|c|c|c|}
\hline Impact Factor: & $\begin{array}{l}\text { ISRA (India) } \\
\text { ISI (Dubai, UAE } \\
\text { GIF (Australia) } \\
\text { JIF }\end{array}$ & $\begin{array}{l}=1.344 \\
=0.829 \\
=0.564 \\
=1.500\end{array}$ & $\begin{array}{l}\text { SIS (USA) } \\
\text { PИНЦ (Russia) } \\
\text { ESJI (KZ) } \\
\text { SJIF (Morocco) }\end{array}$ & $\begin{array}{l}=0.912 \\
=0.234 \\
=3.860 \\
=2.031\end{array}$ & $\begin{array}{l}\text { ICV (Poland) } \\
\text { PIF (India) } \\
\text { IBI (India) }\end{array}$ & $\begin{array}{l}=6.630 \\
=1.940 \\
=4.260\end{array}$ \\
\hline
\end{tabular}

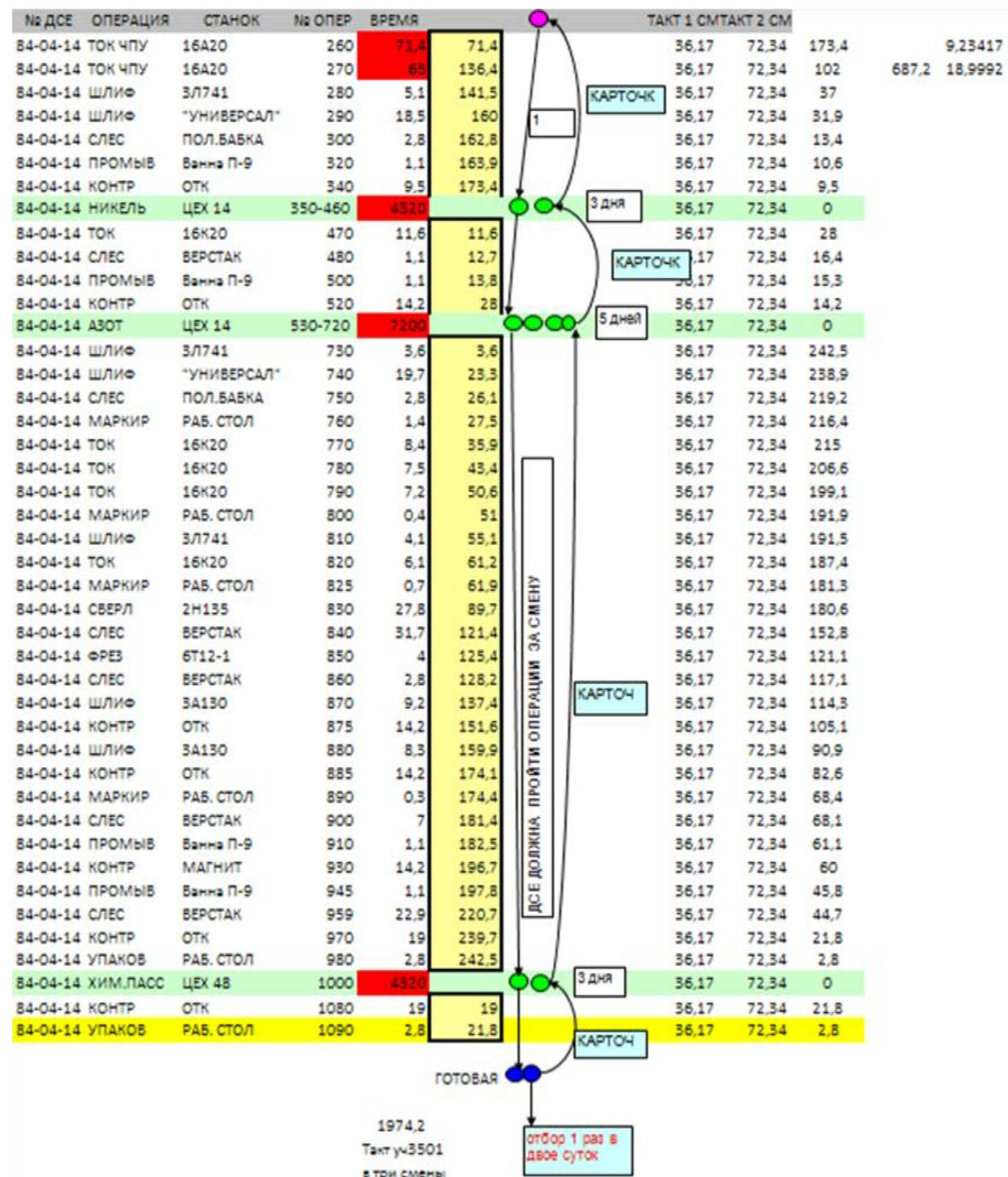

Рисунок 6 - Планирование процесса изготовления детали 84-04-141 «Втулка».

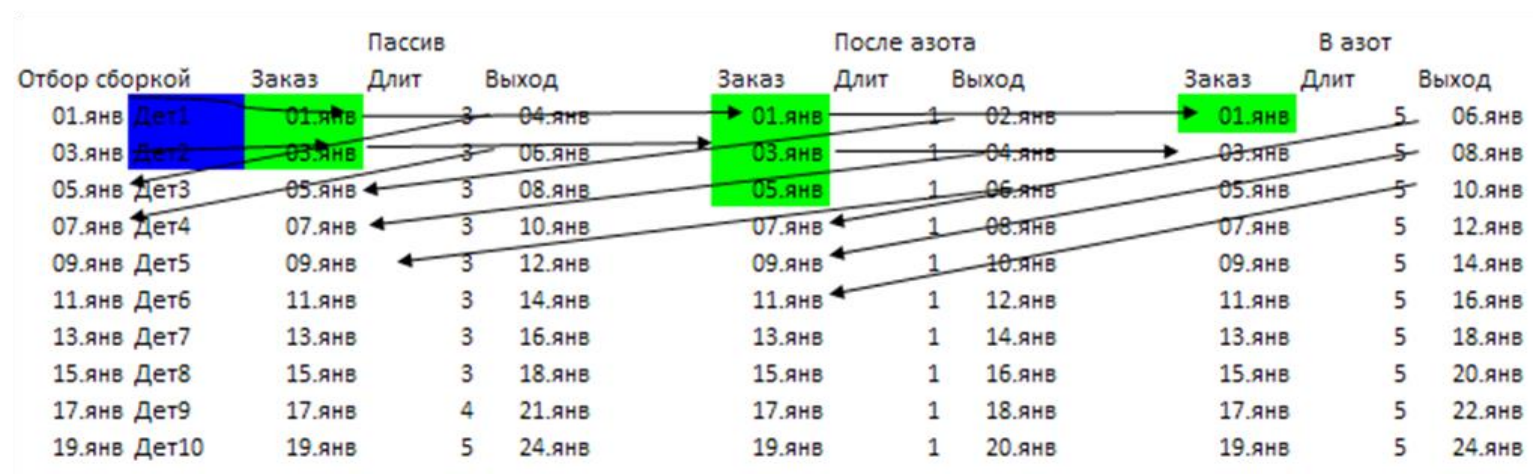

Рисунок 7 - Длительность перемещения деталей.

ISPC Industry and technology,

Philadelphia, USA 
В какой последовательности и в каком количестве последующий участок отбирает ДСЕ, строго в такой последовательности и количестве запускаются ДСЕ в обработку для пополнения задела.

Если производственный цикл изготовления ДСЕ больше, чем период отбора ДСЕ, то по маршруту ДСЕ организуются дополнительные межоперационные заделы ДСЕ. Если ДСЕ забирают каждые 3 дня, то маршрут ДСЕ делится на этапы продолжительностью 3 суток и в начале каждого этапа организуется задел.

Если на одном из этапов существуют проблемы, которые приводят к задержкам, то после такого этапа увеличивают размер операционного задела. Чем «проблемней» этап, тем больше и дороже размер незаконченного производства.

К скрытым потерям на производстве можно отнести:
- продукция производится раньше времени или в большем количестве, чем требуется заказчику;

- значительный избыток сырья, готовых изделий, незаконченное производство;

- лишние перемещения материалов;

- ожидание следующей технологической операции, инструмента, деталей и т.п.;

- дополнительная обработка из-за несоответствующих инструментов или плохой конструкции продукта;

- лишние человеческие движения при подборе материалов, поиск компонентов, инструментов, информации;

- производство, доработка и отбраковка несоответствующей продукции;

- незадействованный потенциал персонала.

Избыток запасов приводит к потерям при выполнении производственного процесса [5]. На рис. 8 представлен пример избытка запасов подшипников в цехе №23.

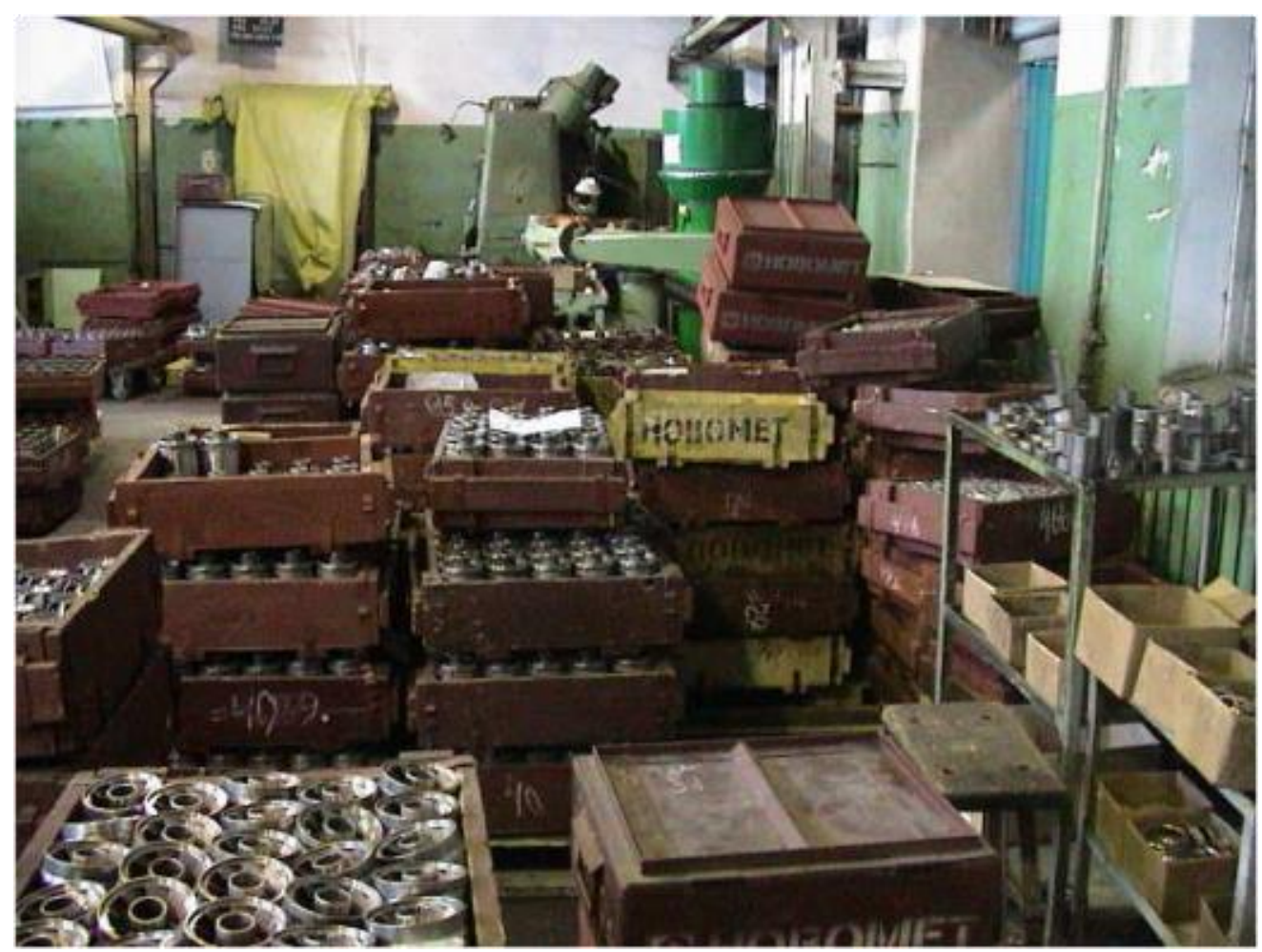

Рисунок 8 - Избыток запасов подшипников в цехе №23.

Для анализа производственных процессов изготовления продукции на заводе применяют карты состояния производства [6]. Карта текущего состояния производства позволяет увидеть потери в потоке создания ценности, схему движения материала и информации. Карта будущего состояния производства представляет собой концепцию улучшения процесса.

Карты текущего и будущего состояния производства подшипников представлены соответственно на рис. 9 и рис. 10. 


\begin{tabular}{l|lr|ll|ll} 
& ISRA (India) & $=\mathbf{1 . 3 4 4}$ & SIS (USA) & $=\mathbf{0 . 9 1 2}$ & ICV (Poland) & $\mathbf{= 6 . 6 3 0}$ \\
Impact Factor: & ISI (Dubai, UAE) $=\mathbf{0 . 8 2 9}$ & PUHL (Russia) & $=\mathbf{0 . 2 3 4}$ & PIF (India) & $=\mathbf{1 . 9 4 0}$ \\
& GIF (Australia) & $=\mathbf{0 . 5 6 4}$ & ESJI (KZ) & $=\mathbf{3 . 8 6 0}$ & IBI (India) & $\mathbf{4 . 2 6 0}$
\end{tabular}

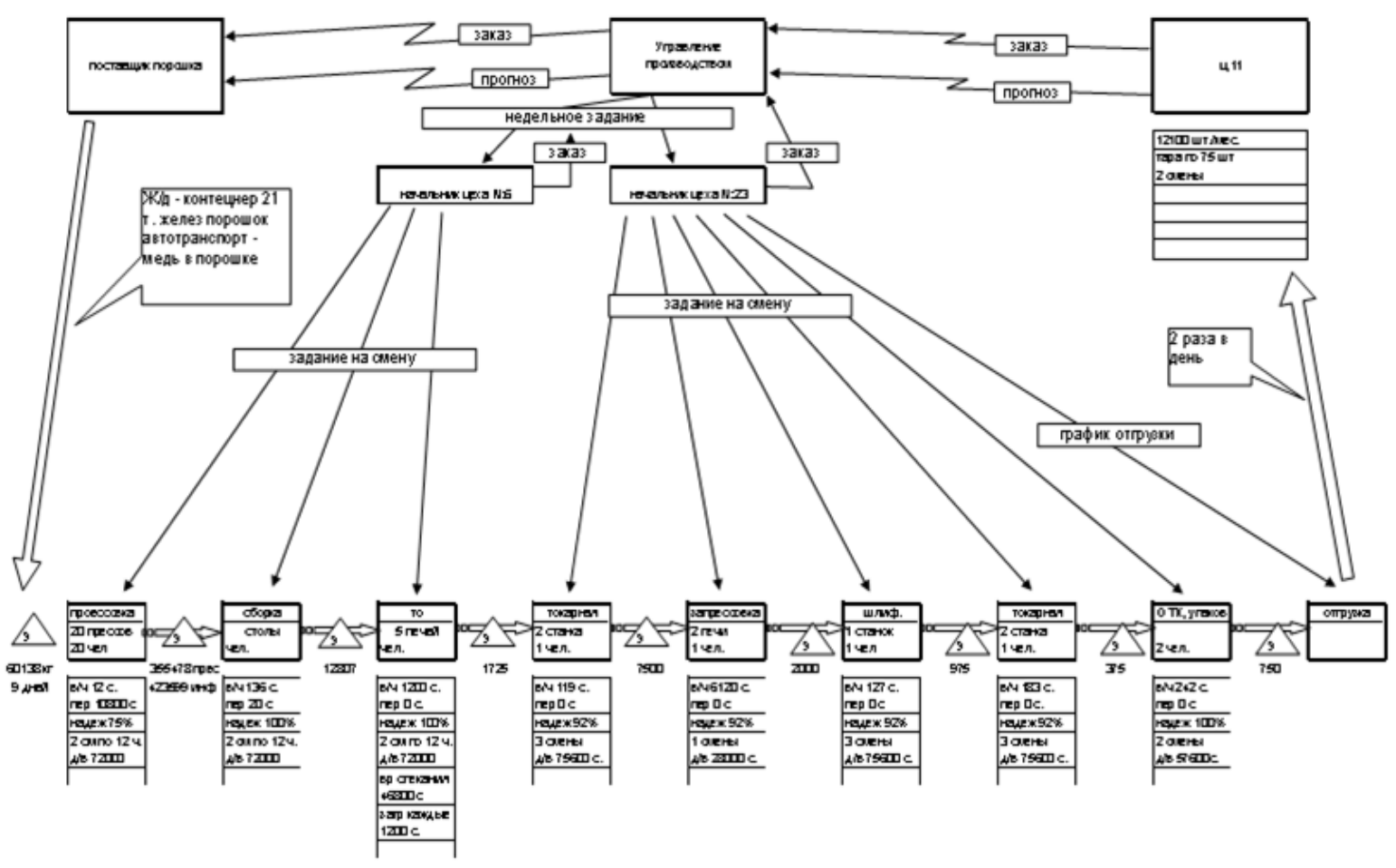

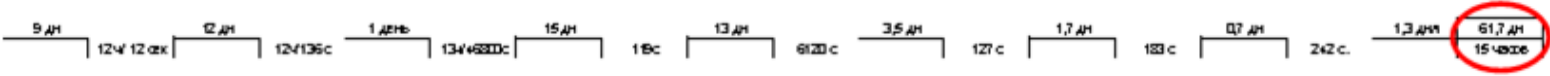

Рисунок 9 - Карта текущего состояния производства подшипников.

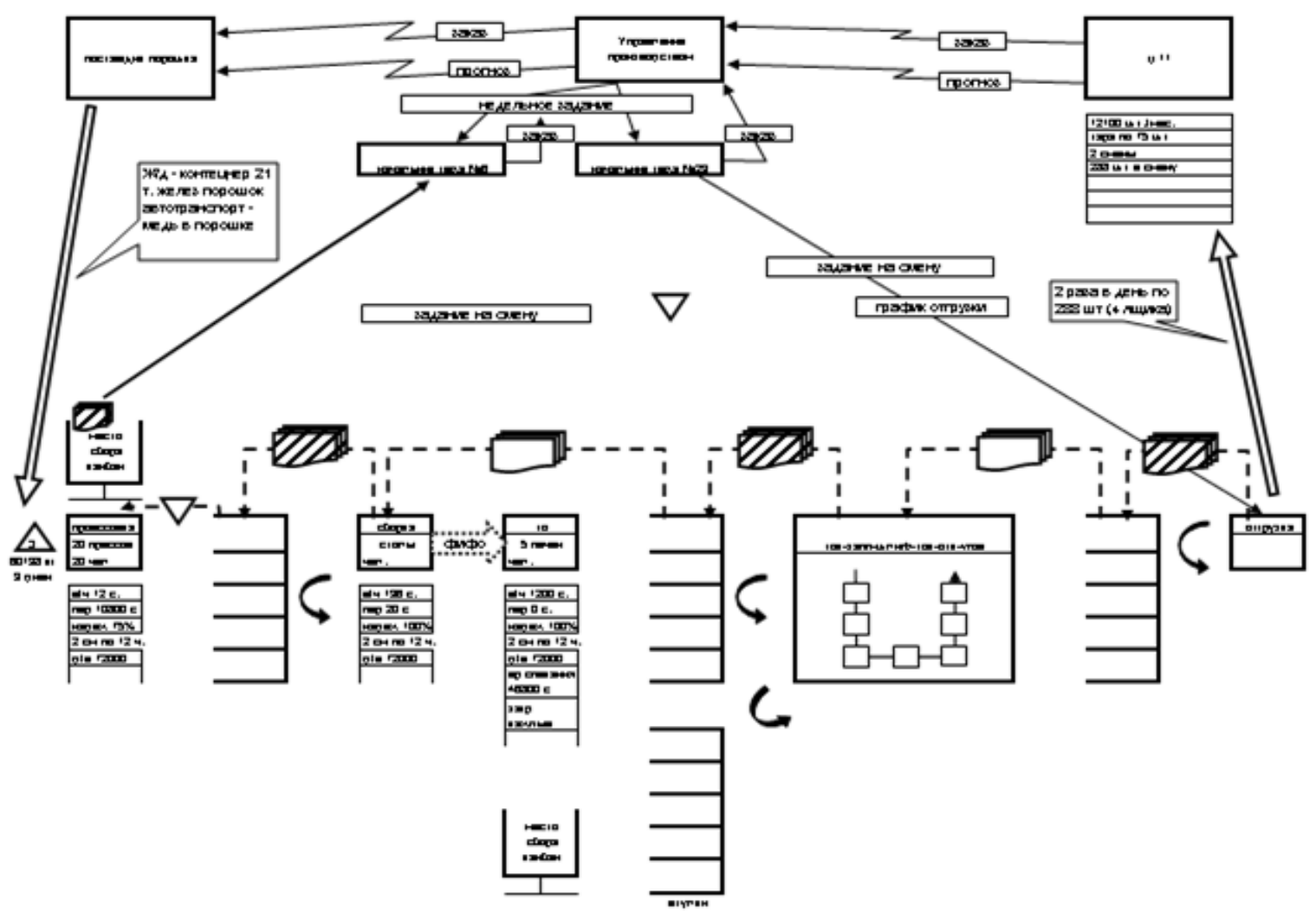

Рисунок 10 - Карта будущего состояния производства подшипников. 


\begin{tabular}{|c|c|c|c|c|c|c|}
\hline Impact Factor: & $\begin{array}{l}\text { ISRA (India) } \\
\text { ISI (Dubai, UAF } \\
\text { GIF (Australia) } \\
\text { JIF }\end{array}$ & $\begin{array}{l}=1.344 \\
=0.829 \\
=0.564 \\
=1.500\end{array}$ & $\begin{array}{l}\text { SIS (USA) } \\
\text { PИНЦ (Russia) } \\
\text { ESJI (KZ) } \\
\text { SJIF (Morocco) }\end{array}$ & $\begin{array}{l}=0.912 \\
=0.234 \\
=3.860 \\
=\mathbf{2 . 0 3 1}\end{array}$ & $\begin{array}{l}\text { ICV (Poland) } \\
\text { PIF (India) } \\
\text { IBI (India) }\end{array}$ & $\begin{array}{l}=6.630 \\
=1.940 \\
=4.260\end{array}$ \\
\hline
\end{tabular}

За месяц необходимо изготавливать 12100 подшипников. Суточное требование - 576.2 деталей. Такт изготовления одного подшипника составляет 45,6 c.

Устойчивость и постоянство в течение длительного периода времени обеспечивается стандартной работой (упрощенной и структурированной). Стандартная работа подразумевает создание схем движения оператора, улучшение процесса посредством подробного анализа взаимодействия работы станков и работы людей [7]. Карта стандартной работы на операцию «Токарная с ЧПУ» представлена на рис. 11.

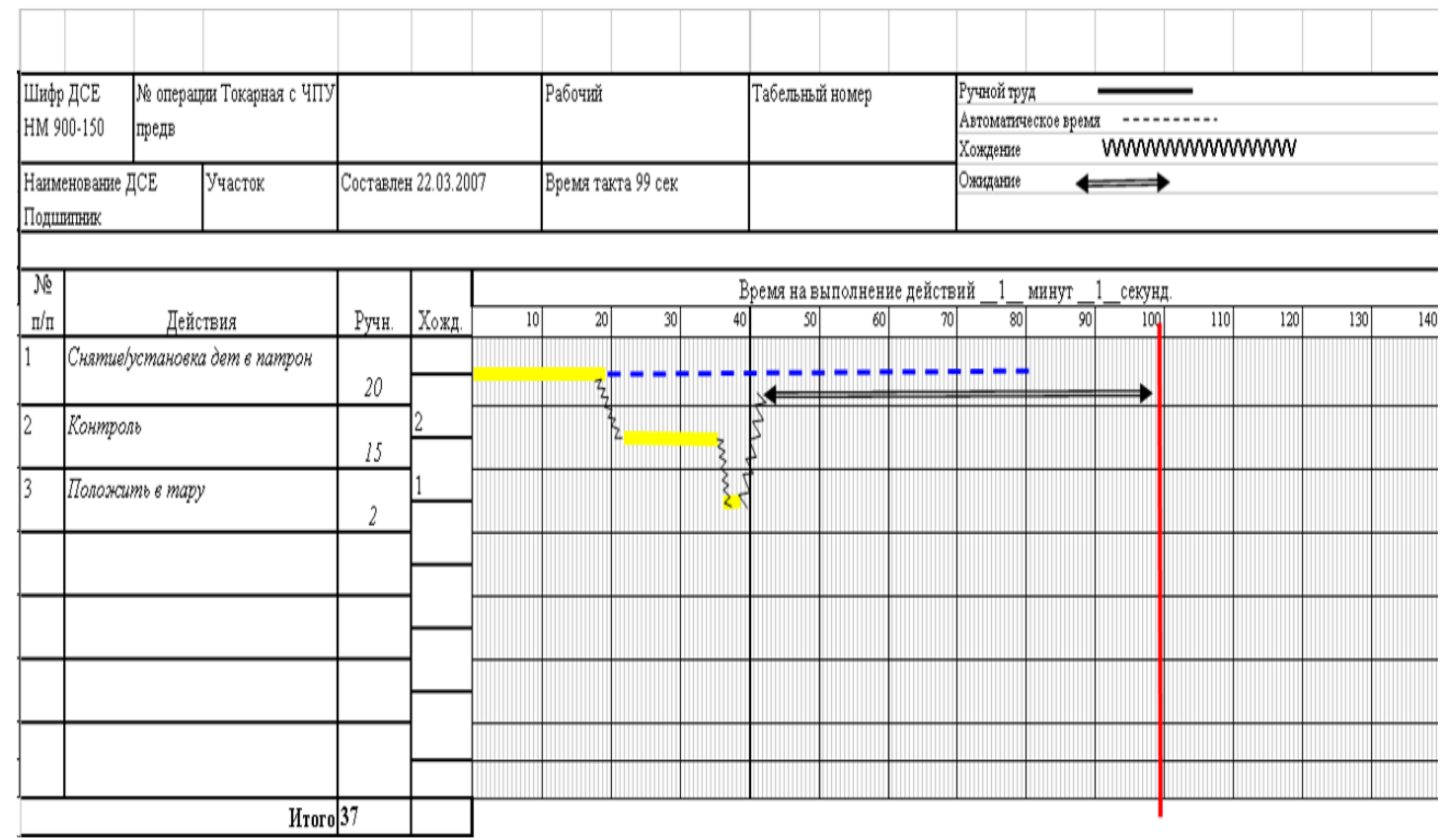

Рисунок 11 - Карта стандартной работы.

Внедрение бережливого производства на ОАО «Завод «Автоприбор» было осуществлено на основании требований к производственной системе, установления четырех этапов для достижения определенного состояния бережливого производства (начальный $\rightarrow$ базовый $\rightarrow$ базовый $+\rightarrow$ превосходство), общего организационного плана и порядка рассмотрения актуальных вопросов связанных с реализацией планов.

Установленная форма для ведения общего организационного плана совершенствования производства представлена на рис. 12.

\begin{tabular}{|c|c|c|c|c|c|c|c|c|c|c|c|c|c|c|c|c|c|}
\hline Дата: & & & & & & & & & & & & & & & & \multirow{3}{*}{$\begin{array}{l}\text { Директор по } \\
\text { прокзводству }\end{array}$} & \multirow{2}{*}{$\begin{array}{l}\text { Финансов } \\
\text { пнректор }\end{array}$} \\
\hline \multicolumn{16}{|l|}{ Руково одитель } & & \\
\hline \multicolumn{16}{|l|}{$\begin{array}{l}\text { Менеджер потока } \\
\text { создания ценности }\end{array}$} & & 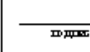 \\
\hline \multirow{2}{*}{$\begin{array}{l}\text { Цепи по каждолу } \\
\text { сежейс тву продуктов }\end{array}$} & \multirow{2}{*}{$\begin{array}{c}\text { Oбласть } \\
\text { процесса } \\
\text { производс } \\
\text { тва }\end{array}$} & \multirow{2}{*}{ Задачи } & \multirow{2}{*}{ Центи (измеркокие) } & \multicolumn{12}{|c|}{ График по меслгам на 2006 год. } & \multirow{2}{*}{$\begin{array}{l}\text { Ответственньй } \\
\text { сотрудник }\end{array}$} & \multirow{2}{*}{$\begin{array}{l}\text { Привле че } \\
\text { специяли } \\
\text { и отдешт }\end{array}$} \\
\hline & & & & 1 & 2 & 3 & 4 & 5 & 6 & 7 & 8 & 9 & 10 & 11 & 12 & & \\
\hline \multirow[t]{2}{*}{ 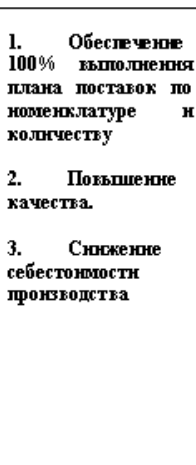 } & 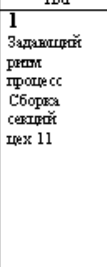 & 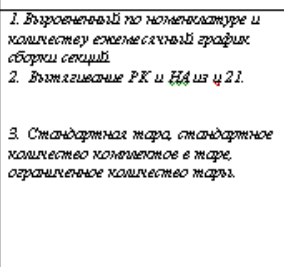 & 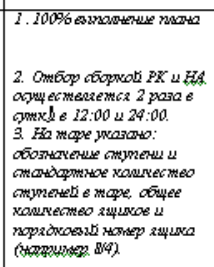 & & & & & & & & & & & & & & \\
\hline & 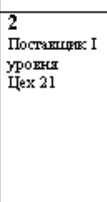 & 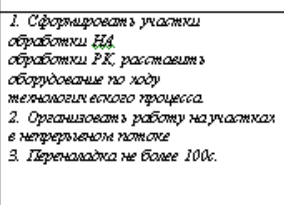 & 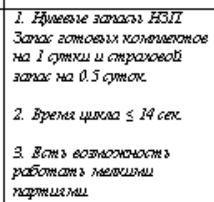 & & & & & & & & & & & & & & \\
\hline
\end{tabular}

Рисунок 12 - План совершенствования производства семейств РК и НА (направляющие аппараты).

ISPC Industry and technology,

Philadelphia, USA 


\begin{tabular}{|c|c|c|c|c|c|c|}
\hline Impact Factor: & $\begin{array}{l}\text { ISRA (India) } \\
\text { ISI (Dubai, UAF } \\
\text { GIF (Australia) } \\
\text { JIF }\end{array}$ & $\begin{array}{l}=1.344 \\
=0.829 \\
=0.564 \\
=1.500\end{array}$ & $\begin{array}{l}\text { SIS (USA) } \\
\text { PИНЦ (Russia) } \\
\text { ESJI (KZ) } \\
\text { SJIF (Morocco) }\end{array}$ & $\begin{array}{l}=0.912 \\
=0.234 \\
=\mathbf{3 . 8 6 0} \\
=\mathbf{2 . 0 3 1}\end{array}$ & $\begin{array}{l}\text { ICV (Poland) } \\
\text { PIF (India) } \\
\text { IBI (India) }\end{array}$ & $\begin{array}{l}=6.630 \\
=1.940 \\
=4.260\end{array}$ \\
\hline
\end{tabular}

ОАО «Завод «Автоприбор» выполняет заказы по изготовлению насосов для различных организаций России. Отгрузка готовых изделий осуществлялась каждые 5 дней в течение двух месяцев:

\section{0 января}

1. Покупатель ООО «Лукойл ТД», 16 наименований изделий, общее количество изделий -69.

2. Покупатель ОАО «Роснефть НК», одно наименование изделия, общее количество изделий -1 .

\section{5 января}

1. Покупатель «Лукойл ТД» (Медведицкая база), одно наименование изделия, общее количество изделий -1 .

2. Покупатель ООО «Нижнеомринская нефть», одно наименование изделия, общее количество изделий -1 .

3. Покупатель ООО «Новомет-Сервис», 10 наименований изделий, общее количество изделий -23.

4. Покупатель ЗАО «Пермглавнефтеснаб», одно наименование изделия, общее количество изделий -2.

5. Покупатель ОАО «Роснефть НК», 18 наименований изделий, общее количество изделий -30.

6. Покупатель ОАО «Сургутнефтегаз», 2 наименования изделий, общее количество изделий - 15.

7. Покупатель ОАО «ТНК-ВР Холдинг», 10 наименований изделий, общее количество изделий - 13.

\section{0 января}

1. Покупатель ЗАО «Пермглавнефтеснаб», одно наименование изделия, общее количество изделий -2.

2. Покупатель ОАО «Славнефть НГК», одно наименование изделия, общее количество изделий -4 .

\section{5 января}

1. Покупатель ООО «Лукойл ТД», 2 наименования изделий, общее количество изделий -5 .

2. Покупатель ООО «Ойл ТехноПамп», 9 наименований изделий, общее количество изделий - 11.

3. Покупатель ЗАО «Пермская инновационно-лизинговая компания», 9 наименований изделий, общее количество изделий - 29.

4. Покупатель «РИТЭКНадымнефть», одно наименование изделия, общее количество изделий -2.

\section{0 января}

1. Внутренний заказчик (ОАО «Завод «Автоприбор»), одно наименование изделия, общее количество изделий -1 .

2. Покупатель «Нефтяная Технологическая Компания», 2 наименования изделий, общее количество изделий -4.

10 февраля

1. Покупатель ООО «Лукойл ТД», 16 наименований изделий, общее количество изделий -63.

2. Покупатель ЗАО «Пермглавнефтеснаб», 6 наименований изделий, общее количество изделий -10 .

3. Покупатель ОАО «Роснефть НК», 11 наименований изделий, общее количество изделий - 15.

\section{5 февраля}

1. Покупатель ОАО «ТНК-ВР Холдинг», 26 наименований изделий, общее количество изделий - 44.

\section{5 февраля}

1. Покупатель ООО «Новомет-Сервис», 3 наименования изделий, общее количество изделий - 18.

Выполним анализ графика сборки насосов за два месяца (рис. 13).
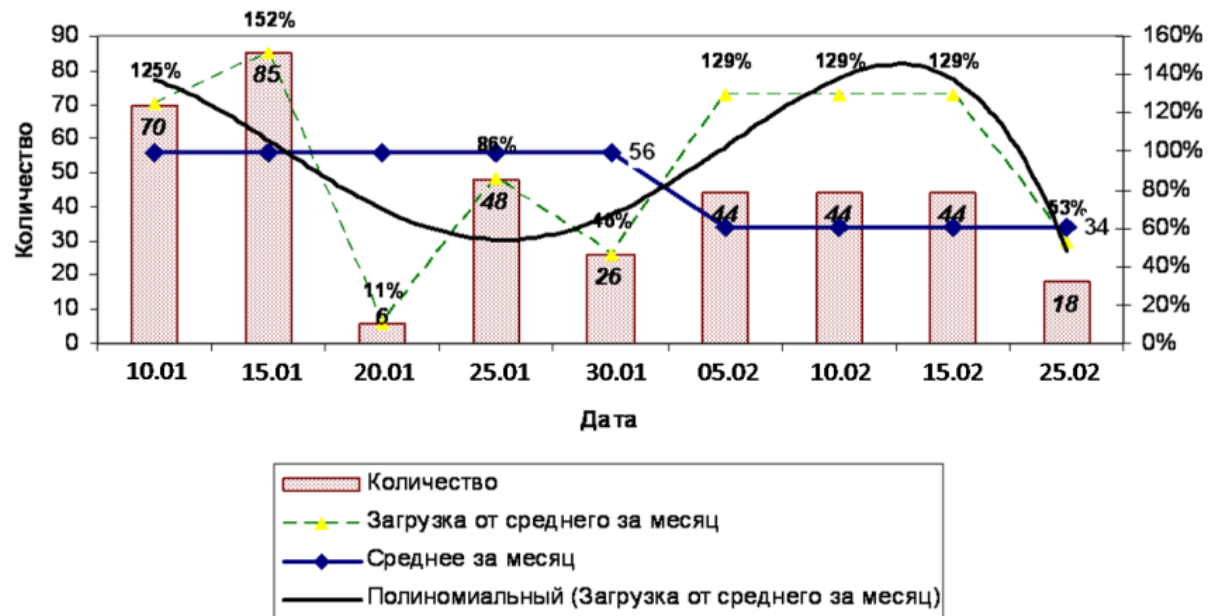

Рисунок 13 - Ритмичность работы сборочного производства насосов за январь - февраль. 


\section{Impact Factor:}

\begin{tabular}{|c|c|c|}
\hline SRA (India) & $=1.344$ & SIS (USA) \\
\hline & & РИНЦ $($ Russia $)=0$ \\
\hline tralia) & $=0.5$ & ESJI $(\mathrm{KZ}) \quad=\mathbf{3 . 8 6 0}$ \\
\hline JIF & $=1.50$ & SJIF $($ Morocco $)=\mathbf{2 . 0 3}$ \\
\hline
\end{tabular}

График сборки насосов не выровнен по номенклатуре и количеству. Корректирующим действием для устранения неритмичности сборочного цеха предусмотрено рассмотрение вопросов, связанных с ритмичной загрузкой цеха №11 на СБП с привлечением группы внедрения
MRP [8]. В табл. 1 представлены данные для определения графика последовательности сборки и обеспечения ритмичности производства. Последовательность выпуска 15-ти изделий номенклатуры А, В и С представлена на рис. 14.

Таблица 1

Основные данные для определения графика последовательности сборки и обеспечения ритмичности производства.

\begin{tabular}{|c|c|c|c|c|c|c|}
\cline { 2 - 6 } \multicolumn{1}{c|}{} & \multicolumn{2}{c|}{ План } & \multicolumn{3}{c|}{} \\
\cline { 2 - 6 } \multicolumn{1}{c|}{} & Изделия & $\mathbf{A}$ & $\mathbf{B}$ & $\mathbf{C}$ & Итого \\
\cline { 2 - 5 } \multicolumn{1}{c|}{} & Кол-во в месяц & 2 & 5 & 8 & 15 & \multicolumn{4}{c|}{} \\
\hline Компл. & \multicolumn{5}{|c|}{} \\
\hline Изделие & Узел 1 & Узел 2 & Узел 3 & Деталь 1 & Деталь 2 \\
\hline $\mathbf{A}$ & 20 & 40 & 2 & 1 & 0 \\
\hline В & 40 & 30 & 3 & 0 & 2 \\
\hline $\mathbf{C}$ & 0 & 0 & 3 & 2 & 4 \\
\hline
\end{tabular}

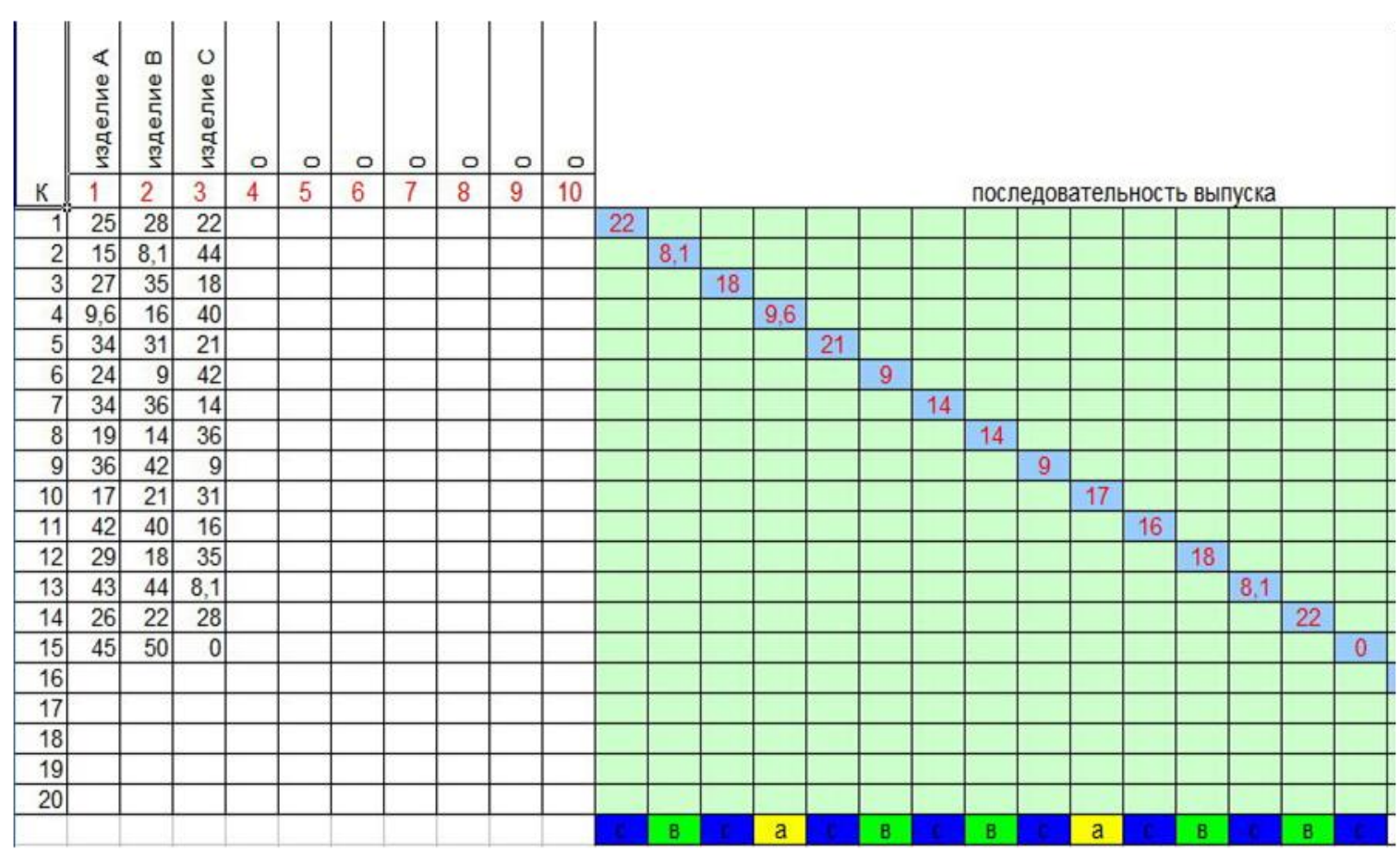

Рисунок 14 - Последовательность выпуска 15-ти изделий.

\section{Заключение}

Анализ рассмотренных производственных процессов позволяет выбрать рациональное расположение технологического оборудования и способ перемещения заготовок. Выделены основные виды потерь при изготовлении продукции и предложены мероприятия по их предупреждению инструментами бережливого производства. Правильность выполненных расчетов подтверждается при сравнении карт текущего и будущего состояния производства изделий. 


\begin{tabular}{l|lrl|l|ll} 
& ISRA (India) & $=\mathbf{1 . 3 4 4}$ & SIS (USA) & $=\mathbf{0 . 9 1 2}$ & ICV (Poland) & $=\mathbf{6 . 6 3 0}$ \\
Impact Factor: & ISI (Dubai, UAE) $=\mathbf{0 . 8 2 9}$ & PUHIL (Russia) $=\mathbf{0 . 2 3 4}$ & PIF (India) & $=\mathbf{1 . 9 4 0}$ \\
& GIF (Australia) & $\mathbf{0 . 5 6 4}$ & ESJI (KZ) & $=\mathbf{3 . 8 6 0}$ & IBI (India) & $\mathbf{= 4 . 2 6 0}$ \\
& JIF & $\mathbf{1 . 5 0 0}$ & SJIF (Morocco) & $=\mathbf{2 . 0 3 1}$ & & \\
\hline
\end{tabular}

\section{References:}

1. (2017) Manufacturing process. Available: https://ru.wikipedia.org/wiki/Производственн ый процесс (Accessed: 27.04.2017).

2. (2017) Lean manufacturing. Available: https://en.wikipedia.org/wiki/Lean_manufacturi ng (Accessed: 27.04.2017).

3. (2015) GOST 56407-2015. Lean manufacturing. Basic methods and tools.

4. (2017) The technique of drawing up of production plans in a single information space of automated control system of the enterprise. Available:

http://www.umpro.ru/index.php?art_id 1=210 \&group id 4=70\&page $\mathrm{id}=17$ (Accessed: 27.04.2017)
5. Smirnov VA, Antonova II, Antonov SA, Dmitrieva GR (2013) Relationship between hidden losses and lean manufacturing tools. Competency, 2/103. - 36-39 p.

6. (2017) VSM - Value stream mapping. Available: $\quad$ http://www.uppro.ru/specprojects/shkola-menedjera/kpcsvsm.html (Accessed: 27.04.2017).

7. (2017) Standardized work chart. Available: http://avcc.ru/library/encyclopedia/standardized work (Accessed: 27.04.2017).

8. (2017) Material requirements planning. Available:

https://en.wikipedia.org/wiki/Material_requirem ents planning (Accessed: 27.04.2017). 